\title{
Haftanın Günü ve Ocak Ayı Anomalilerinin BIST 100 ile KAT 30 Endekslerinde Tespiti
}

\section{Determination of Day of the Week and January Anomalies in BIST 100 and KAT 30 Indexes}

\author{
Arş. Gör. Dr. Hidayet GÜNEŞ iD 1
}

\begin{abstract}
$\ddot{\mathbf{O} z}$
Takvim anomalisi, menkul kıymet fiyatlarındaki değişikliklerin belirli bir trend ya da tutarlı bir kalıp sonucunda meydana gelmesi olarak ifade edilmektedir. Fama Etkin Piyasa Hipotezi'nde yatırımcıların, çeşitli yatırım stratejileri kullanarak aşırı kazanç elde edemeyeceklerini ifade etmektedir. Ancak yatırımcılar, finansal piyasalardaki takvim etkilerini dikkate alarak ortalama piyasa getirisi üzerinde bir kazanç elde edebilmektedirler. Çalışma, Türkiye hisse senedi piyasasının İslami ve konvansiyonel endekslerinde haftanın günü ve Ocak ayı etkilerinin olup olmadığını tespit etmek için yapılmaktadır. İslami endeks olarak Katılım 30, konvansiyonel endeks olarak da Borsa İstanbul 100 endeksi seçilmiştir. Kukla değişkenli EGARCH $(1,1)$ model sonuçları, BIST 100 endeks getirisi üzerinde haftanın günü etkisinin olmadığını ancak KAT 30 endeks getirisinde Pazartesi ve Çarşamba günlerinin negatif etkisinin olduğunu göstermektedir. Ocak ayının ise her iki endeks getirileri üzerinde negatif etkisinin olduğu belirlenmiştir. Volatilite üzerinde ise, BIST 100 endeksinde Pazartesi ve Çarşamba günlerinin, KAT 30 endeksinde de Pazartesi gününün negatif etkisinin olduğu tespit edilmiştir. Ocak ayının ise, her iki endeks volatilitesi üzerinde herhangi bir etkisinin olmadığı belirlenmiştir. Asimetri parametresi olan $\gamma$, her iki endeks içinde anlamlı ve negatif değerde sonuç vermiştir. Bu sonuç, negatif bilgi şoklarının pozitif bilgi şoklarına göre volatiliteyi daha fazla artırdığı anlamına gelmektedir.
\end{abstract}

Anahtar Kelimeler: Takvim anomalisi, ocak ayı etkisi, haftanın günü etkisi, EGARCH modeli

Makale Türü: Araştırma

\begin{abstract}
Calendar anomaly is defined as the occurrence of changes in securities prices as a result of a certain trend or a consistent pattern. Fama in the Efficient Market Hypotesis, it states that investors cannot gain excessive profits by using various investment strategies. However, investors can earn above the average market return taking into account the calendar anomalies in the financial markets. Study, Islamic and conventional indexes in the stock markets of Turkey and is made to determine whether day of the week and the January effect. Katılım 30 was chosen as the Islamic index and Borsa Istanbul 100 index was chosen as the conventional index. Dummy variable EGARCH $(1,1)$ model results show that there is no day-of-week effect on the BIST 100 index return, but Monday and Wednesday have a negative effect on the KAT 30 index return. It was determined that January had a negative effect on the returns of both indices. On the volatility, it was determined that Monday and Wednesday in the BIST 100 index and Monday in the KAT 30 index had a negative effect. It has been determined that January has no effect on the volatility of both indices. The asymmetry parameter $\gamma$, gave significant and negative results for both indices. This result means that negative information shocks increase volatility more than positive information Shocks.
\end{abstract}

Keywords: Calendar anomaly, January effect, day of the week effect, EGARCH model

Paper Type: Research

${ }^{1}$ Burdur Mehmet Akif Ersoy Üniversitesi, İktisadi ve İdari Bilimler Fakültesi, hgunes@mehmetakif.edu.tr.

Atıf için (to cite): Güneş, H. (2021). Haftanın günü ve Ocak ayı anomalilerinin BIST 100 ile KAT 30 endekslerinde tespiti. Afyon Kocatepe Üniversitesi Sosyal Bilimler Dergisi, 23(1), 236-248. 


\section{Giriş}

Finansal piyasalarda takvim anomalilerinin varlığı üzerine yapılan çalışmalar son yıllarda artış göstermektedir. Takvim anomalisi, menkul kıymet fiyatlarındaki değişikliklerin belirli bir trend ya da tutarlı bir kalıp sonucunda meydana gelmesi olarak ifade edilmektedir. Bu anomali, çoğunlukla bir takvim yılı içerisinde belirli aralıklarla oluşan düzenli kalıplar veya mevsimsel hareketlerin sonucunda oluşmaktadır. Bunun sonucunda, yatırımcılar açısından hisse senedi piyasaları belirli aralıklarla tahmin edilebilir olabilmektedir. Bu düzenli tahminlere takvim anomalisi adı verilmektedir. Bu anomali veya kalıplar sayesinde, piyasa oyuncuları tahminde bulunarak piyasada anormal kazanç elde edebilmektedirler. Bu durum, Etkin Piyasa Hipotezi'nin hisse senedi piyasasını yenmenin zor olduğu ve yatırımeı için anormal kazancın olmadığı ön koşuluna aykırı düşmektedir. Takvim anomalileri haftanın günü etkisi, Ocak ayı etkisi, yılın ayı etkisi, tatil etkisi, ay dönümü etkisi gibi anomalilerden meydana gelmektedir (Tajinder, 2019, s. $10)$.

Fama Etkin Piyasa Hipotezi’nde yatırımcıların, çeşitli yatırım stratejileri kullanarak aşırı kazanç elde edemeyeceklerini ifade etmektedir. Ancak yatırımcılar, finansal piyasalardaki takvim etkilerini dikkate alarak ortalama piyasa getirisi üzerinde bir kazanç elde edebilmektedirler. Finans literatürü kapsamında yapılan takvim anomalisi çalışmaları, yatırımcılara belirli gün veya aylarda hisse senedi fiyat hareketlerini öngörebilmeleri için yol gösterici nitelikte olabilmektedirler (Yardımcı \& Erdem, 2020: 195). Anomaliler, etkin olmayan piyasaları ortaya koymakta yardımcı olan bir kavramdır. Anomalilerin bir kısmı sadece bir kez görünüp sonrasında ortadan kaybolurken, bazıları ise sıklıkla meydana gelmekte ve süreklilik göstermektedir (Latif vd., 2011, s. 3).

Etkin Piyasa Hipotezi, menkul kıymet fiyatlarının rassal yürüyüş sergilediğini ve halka açık olan bilgileri kullanarak menkul kıymetin gelecekteki getirilerini tahmin edebilmenin mümkün olmadığını belirtmektedir. Yani, hisse senedi fiyatlarındaki değişiklikleri, onun geçmiş fiyat davranışlarına bakarak öngörebilmek imkânsız olmaktadır. Son zamanlarda araştırmacılar tarafından gerçekleştirilen farklı tarzda testler sayesinde, sonucun daha farklı olabileceği ortaya koyulmuştur. Rozeff \& Kinney (1976), 1904 ile 1974 tarihleri arasında New York Borsası fiyatlarının eşit ağırlıklı bir endeksinde mevsimsel kalıpların olduğunu göstermişlerdir. Ocak ayındaki ortalama aylık getiriyi yaklaşı \% 3,5 olarak hesaplarken, diğer ayların ortalamasını yaklaşık \% 0,5 olarak tespit etmişlerdir. Bu sonuç, sadece Ocak ayındaki getirilerin yıllık getirilerin üçte birinden daha fazlasını oluşturduğunu ortaya koymaktadır (Thaler, 1987, s. 199). Ocak ayı etkisi, Ocak ayı boyunca hisse senedi fiyatlarında mevsimsel olarak bir artışın gerçekleştiğini ifade etmektedir. Haftanın günü etkisi, belirli bir hafta içi gün veya günlerde hisse senetleri getirilerinin mevsimsel olarak, uzun bir süre boyunca haftanın diğer günlerine kıyasla sürekli olarak daha yüksek veya daha düşük getiri sağlanan gün veya günlerin varlığını belirtmektedir. Literatürde, çoğunlukla Pazartesi ve Cuma günü etkileri görülmektedir. Cuma günü pozitif getiri söz konusu olurken Pazartesi tam tersi negatif getiri ortaya çıkmaktadır (Tajinder, 2019, s. 10-11).

Yapılan çalışmaların çoğunda (Choudhry 2000, Konak ve Kendirli 2014, Arı ve Yüksel 2016, Jebran \& Chen 2017, Yardımc1 \& Erdem 2020) haftanın günü veya Ocak ayı etkileri araştırılmaktadır. Hisse senedi endekslerinde, getirilerin haftanın belirli günlerine göre değişim sergilediği görülmektedir. Yapılan çalışmalarda (Atakan 2008, Korkmaz vd. 2010, Karcıoğlu ve Özer 2017, Anjum 2020), Pazartesi günkü ortalama getirinin diğer günlerin ortalama getirisinden önemli derecede düşük olduğu tespit edilmiştir. Hisse senedi getirilerinin volatilitesinde haftanın gününe göre değişkenlik olup olmadığını ve yüksek (düşük) getirinin belirli bir gün için karş1lık gelen yüksek (düşük) getiriyle ilişkili olup olmadığını bilmek önemlidir. Bu bilgilere sahip olmak, yatırımcıların oynaklıktaki haftalık değiş̧imlerini dikkate alarak portföylerini ayarlamalarına olanak sağlayabilmektedir (Berument \& Kıymaz, 2001, s. 182). 
Çalışma, Türkiye hisse senedi piyasasının İslami ve konvansiyonel endekslerinde haftanın günü ve Ocak ayı etkilerinin olup olmadığını tespit etmek için yapılmaktadır. İslami endeks olarak Katılım 30, konvansiyonel endeks olarak da Borsa İstanbul 100 endeksinin 7 Ocak 2011 ile 24 Temmuz 2020 tarihleri arasındaki günlük kapanış fiyatları üzerinde analiz gerçekleştirilmiştir. Bu tarih aralığının seçilmesinin sebebi ise, Katılım 30 endeksinin o tarihten itibaren başlaması ve borsa endekslerinden iki sıfır atılmadan önceki son iş günü olmasıdır. Endeks getiri serilerine, EGARCH modeli kullanılarak analizler gerçekleştirilmiştir. Asimetrik model olmasından dolayı, negatif veya pozitif bilgi şoklarının etkileri de ortaya çıkarılmak istenmektedir. Çalışma, analiz edilen endeksler arasında bir karşılaştırma yapılarak gerçekleştirilen çalışmaların çok az sayıda olmasından dolayı konu ile alakalı literatürü genişleteceği ve derinleştirileceği düşünülerek yapılmıştır. Ayrıca bu endeksler üzerinde işlem yapan yatırımcılara, almak istedikleri yatırım pozisyonu hakkında da bilgiler verebilecektir.

Çalışma beş bölümden meydana gelmektedir. Birinci bölümde giriş, ardından konu ile alakalı literatüre değinilmektedir. Üçüncü bölümde ekonometrik metodoloji sonrasında araştırmanın yöntem ve bulguları yer almakta ve son olarak da sonuç bölümü ile çalışma tamamlanmaktadir.

\section{Literatür}

Takvim anomalileri üzerine gerçekleştirilen çalışmalar son yıllarda artış eğilimindedir. $\mathrm{Bu}$ bölümde, hisse senedi piyasası endekslerinde haftanın günü ve Ocak ayı etkisini GARCH türü modellerle analiz eden çalışmalara yer verilmiştir.

Choudhry (2000), gelişmekte olan 7 Asya (Hindistan, Malezya, Endonezya, Filipinler, Güney Kore, Tayvan ve Tayland) borsasının getiri ve volatilitesinde haftanın günü etkisini, Ocak 1990 ile Haziran 1995 tarihleri arasındaki günlük kapanış fiyatları üzerinde GARCH modelini kullanarak araştırdığı çalışmada, borsa getiri ve volatilitesinde önemli derecede haftanın günü etkisinin olduğunu ve sonuçların yedi endeks içinde farklılık gösterdiğini belirlemiştir.

Berument \& Kiymaz (2001), S\&P 500 borsa endeksinin getiri ve volatilitesinde haftanın günü etkisini Ocak 1973 ile Ekim 1997 tarihleri arasındaki günlük kapanış fiyatları üzerinde OLS, GARCH ve M-GARCH modellerini kullanarak araştırdıkları çalışmada, getiri ve volatilitede haftanın günü etkisinin olduğunu belirlemişlerdir. Ayrıca, en yüksek getirinin Çarşamba en düşük getirinin Pazartesi ve en yüksek volatilitenin Cuma en düşük volatilitenin ise Çarşamba günü gerçekleştiğini tespit etmişlerdir.

Atakan (2008), İMKB Bileşik-100 Endeksi'nin 3 Temmuz 1987 ile 18 Temmuz 2008 tarihleri arasındaki günlük kapanış fiyatları üzerinde haftanın günü ve ocak ayı etkisinin varlığını GARCH modeli kullanarak araştırdığı çalışmada, Ocak ayı etkisinin olmadığını, Cuma günleri endeks getirisinin diğer günlere göre ortalamadan yüksek, Pazartesi günü ise düşük olduğu sonucuna ulaşmıştır.

Korkmaz vd. (2010), İstanbul Menkul Kiymetler Borsas1 (IMKB) 100 endeks getirisi üzerinde yaz saati uygulaması ve hafta sonu anomalilerinin etkilerini Ekim 1987 ile Haziran 2009 tarihleri arasındaki günlük kapanış değerleri üzerinde GARCH tipi modeller kullanarak araştırdıkları çalışmada, Pazartesi günleri ortalama getirinin daha düşük olarak gerçekleştiğini ve hafta sonu anomalisinin varlığını tespit etmişlerdir.

Konak ve Kendirli (2014), BİST 100 Endeksi'nde Ocak 2005 ile Aralık 2012 tarihleri arasındaki günlük kapamış fiyatları üzerinde haftanın günü etkisinin varlığını GARCH $(1,1)$ modeli kullanarak belirlemek istedikleri çalışma sonucunda, Pazartesi gününün $\% 10$ anlamlılık düzeyinde anlamlı ve negatif getiri sağladığını belirlemişlerdir.

Arı ve Yüksel (2017), BIST 100'de 3 Ocak 2003 ile 1 Temmuz 2016 tarihleri arasındaki günlük kapanış fiyatları üzerinde haftanın günü etkisinin olup olmadığını GARCH ve EGARCH modellerini kullanarak belirlemek istedikleri çalışmada, haftanın günü etkisinin olmadığını, 
istatistiki olarak anlamlı olmasa da Perşembe günü getirilerinin diğer günlere nazaran daha yüksek olduğunu belirlemişlerdir.

Güç vd. (2016), BİST 100 Birleşik Endeksi’nin İkincil Piyasa'daki 1 Ocak 2002 ile 30 Kasım 2013 tarihleri arasındaki günlük kapanış fiyatları üzerinde haftanın günü etkisinin varlığını OLS, ARCH, ve GARCH modellerini kullanarak belirlemek istedikleri çalışmada, Perşembe ve Cuma günlerindeki getirilerin anlamlı ve en yüksek olduğunu tespit etmişlerdir.

Giovanis (2016), 51 ülkeye ait toplam 55 adet hisse senedi endeksi üzerinde simetrik GARCH ve asimetrik GARCH (EGARCH ve GJR-GARCH) modelleri yardımıyla yılın ayı etkisini, farklı başlangıç tarihleri ile 31 Aralık 2009 tarihleri arasındaki günlük kapanış değerlerini kullanarak araştırdığ 1 çalışmada, 20 hisse senedi endeksinde Aralık ayı etkisinin olduğunu ve bu ayda yüksek pozitif getiriler bulunduğunu belirlemiştir. Ayrıca, Şubat ayının 9 borsada ve Ocak ayının 7 borsada etkisinin olduğunu tespit etmiştir.

Karcığlu ve Özer (2017), BIST-100, BIST-Hizmet, BIST-Mali, BIST-Sınâ̂, BISTTeknoloji endekslerinin 2 Ocak 2002 ile 30 Aralık 2016 tarihleri arasındaki günlük kapanış fiyatları üzerinde haftanın günleri etkisini ARCH-GARCH modellerini kullanarak araştırdıkları çalışmada, haftanın günü etkisini olduğunu ve 5 endeks üzerinde de Pazartesi gününün negatif getiri, BIST Sınai endeksi hariç diğer endekslerde Çarşamba gününün pozitif getiri sağladığını belirlemişlerdir.

Jebran \& Chen (2017), Pakistan İslami hisse senedi piyasasında Ocak ay1, İslami takvim, haftanın günü, ay ortası, ayın zamanı ve ayın dönüşü etkilerini 30 Eylül 2008 ile 30 Haziran 2015 tarihleri arasındaki günlük veriler üzerinde GARCH modelini kullanarak araştırdıkları çalışmada, Ocak ayı ve Ramazan ayı etkisinin olmadığını, ancak diğer anomalilerin endeks getiri ve volatilitesinde etkisinin olduğunu belirlemişlerdir.

Öncü vd. (2017), BIST-100 endeksinde haftanın günü anomalisinin varlığını 3 Ocak 2005 ile 6 Kasım 2015 tarihleri arasındaki günlük kapanış fiyatları üzerinde GARCH $(1,1)$ modelini kullanarak tespit etmek istedikleri çalışmada, haftanın günü anomalisine rastlamamışlardır.

Caporale \& Zakirova (2017), Rusya hisse senedi piyasası MICEX endeksinin 22 Eylül 1997 ile 14 Nisan 2016 tarihleri arasındaki günlük kapanış değerleri üzerinde Ocak ayı, haftanın günü ve ay dönümü etkilerini OLS, GARCH, EGARCH ve TGARCH modellerini kullanarak araştırdıkları çalışmada, ham getiriler dikkate alındığında GARCH ve EGARCH modeli sonucunda Ocak ayı etkisinin, GARCH ve TGARCH modeli sonucunda haftanın günü ve GARCH, EGARCH ve TGARCH modelleri sonucunda da ay dönümü etkilerinin olduğunu ortaya koymuştur. Ancak işlem maliyetleri göz önüne alındığında, bu tür anomalilerin ortadan kalktığını tespit etmişlerdir.

Öztürk vd. (2018), BIST 100 ve KAT30 endeksleri getiri ve volatilitesinde haftanın günleri, Ocak ayı ve Ramazan etkisinin olup olmadığını 7 Ocak 2011 ile 8 Ağustos 2017 tarihleri arasındaki günlük kapanış fiyatları üzerinde OLS ve GARCH modellerini kullanarak araştırdıkları çalışmada, hiçbir anomalinin geçerli olmadığı sonucuna ulaşmışlardır.

Kinateder vd. (2019), Brezilya, Rusya, Hindistan, Çin ve Güney Afrika hisse senedi piyasa endekslerinin 1996 ile 2018 tarihleri arasındaki günlük kapanış fiyatları üzerinde GARCH, GJR-GARCH ve ortalamada GARCH modellerini kullanarak yılın ayı, ay dönümü, haftanın günü ve tatil etkilerini araştırdıkları çalışmada, Salı günü haftanın günü etkisinin olduğunu, ay dönümü etkisinin olduğunu ancak Ocak ayı etkisinin bulunmadığını ve tatil etkisinin genel olarak olmadığını tespit etmişlerdir.

Jindal (2019), Hindistan hisse senedi piyasa endekslerinden olan S\&P CNX 500 endeksinin Ocak 2008 ile Aralık 2018 tarihleri arasındaki günlük kapanış fiyatları üzerinde OLS ve GARCH modellerini kullanarak çeşitli takvim anomalilerini araştırdığ günü etkisinin Hindistan piyasası için var olduğunu tespit etmiştir. 
Khan \& Rabbani (2019), Japonya hisse senedi piyasası TOPIX ve Nikkei 225 endekslerinin sırasıyla Ocak 1977 ve Ocak 1970 ile Mart 2017 tarihleri arasındaki günlük kapanış fiyatları üzerinde OLS ve GARCH modellerini kullanarak haftanın günü, Ocak ayı, ay dönümü gibi anomalileri Yukarı piyasa koşulları (Son 24 ay boyunca kümülatif getirilerin pozitif olduğu piyasa) ve Aşağı piyasa koşullarını (Son 12 ay boyunca kümülatif getirilerin negatif olduğu piyasa) dikkate alarak inceledikleri araştırmada, araştırdıkları tüm anomalilerin Yukarı piyasa koşullarında belirginleştiğini ancak Aşağı piyasa koşullarında hiçbir zaman ortaya çıkmadıklarını tespit etmişlerdir.

Anjum (2020), Pakistan hisse senedi piyasası üzerinde haftanın günü, Ocak ve Temmuz ayı ve hafta sonu etkilerinin olup olmadığını belirleyebilmek için 2 Ocak 2004 ile 30 Nisan 2019 tarihleri arasındaki günlük, haftalık ve aylık kapanış fiyatları üzerinde en küçük kareler, ARCH ve ortalama EGARCH modellerini kullanarak gerçekleştirdiği çoklu regresyon analizi sonucunda, haftanın günü etkisini olduğunu ve Cuma günü en yüksek, Pazartesi ise en düşük getirilerin bulunduğu günler olarak tespit etmiştir. Ocak ve Temmuz ayı etkilerinin ise var olmadığını belirlemiştir.

Singh \& Das (2020), Hindistan menkul kıymetler borsasında işlem gören BSE Bilgi Teknolojileri ve BSE Banka endekslerinin 2010 - 2019 tarihleri arasındaki günlük kapanış fiyatları üzerinde OLS, GARCH, TGARCH ve EGARCH modellerini kullanarak takvim etkisinin varlığını araştırdıkları çalışmada, Ocak ayı ve ay dönümü etkilerinin endekslerin getiri ve volatilitesinde var olduğu sonucuna ulaşmışlardır.

Khanh \& Dat (2020), Vietnam hisse senedi piyasa endeksinin 4 Mart 2002 ile 3 Mart 2017 tarihleri arasındaki günlük kapanış fiyatları üzerinde OLS ve GARCH modellerini kullanarak takvim anomalisini araştırdıkları çalışmada, OLS sonuçlarına göre endeksin Ocak ayında yükseldiğini, GARCH sonucuna göre de OLS sonuçlarına ek olarak Kasım ayında düştüğünü belirlemişlerdir.

Yardımcı \& Erdem (2020), ağırlıklı olarak Müslüman nüfusa sahip olan dünya çapında 19 ülkenin hisse senedi piyasaları endekslerinin 1 Ocak 2005 ile 1 Ocak 2015 tarihleri arasındaki günlük kapanış değerleri üzerinde haftanın günü etkisini GARCH modeli kullanarak araştırdıkları çalışmada, analize tabi olan ülkelerin çoğunda haftanın günü etkisinin olduğunu belirlemişlerdir.

Literatür kapsamında ya sadece konvansiyonel hisse senedi piyasası ya da İslami hisse senedi piyasası üzerine yapılan çalışmalara rastlanmıştır. Çok az sayıda çalışma, bu iki endeks türleri arasında bir karşılaştırma yaparak analiz gerçekleştirmiştir. Ayrıca, Türkiye özelinde asimetrik model kullanarak bu tür karşılaştırmayı gerçekleştiren çalışmaya rastlanmadığı için, çalışma konu ile alakalı literatüre farklılık katacağı varsayılmıştır.

\section{Ekonometrik Metodoloji}

Finansal zaman serilerinde, hata terimlerinin büyük bir kısmının değiş̧en varyans özelliği göstermesinden dolayı, doğrusal modeller kullanılarak oluşturulan regresyon katsayılarının yansız öngörüde bulunmasına rağmen yanlış bir model oluşturulabilmektedir (Engle, 2001, s. 157). Bu konuyu göz önünde bulundurarak, geleneksel modellerden ziyade ARCH türevi modeller yardımıyla analizlerin gerçekleştirilmesi daha doğru sonuçların alınabilmesini sağlamaktadır.

Engle (1982), ARCH modelini:

$\mathrm{h}_{\mathrm{t}}=\alpha_{0}+\alpha_{1} \varepsilon_{\mathrm{t}-1}^{2}+\alpha_{2} \varepsilon_{\mathrm{t}-2}^{2}+\ldots+\alpha_{\mathrm{q}} \varepsilon_{\mathrm{t}-\mathrm{q}}^{2}+\mathrm{v}_{\mathrm{t}}$

şeklinde formüle etmektedir. Formülde yer alan $\mathrm{v}_{\mathrm{t}}$ beyaz gürültü sürecini ve $\mathrm{q}$ da gecikme süresini ifade etmektedir (Engle, 1982, s. 997).

ARCH modelinin, finansal zaman serilerinin koşullu varyansını modellemede yetersiz kalması sonucunda, modelin geliştirilmesi gerektiğini düşünen Bollerslev (1986), 
Genelleştirilmiş Otoregresif Koşullu Değişen Varyans (GARCH) modelini literatüre kazandırmıştır. GARCH modeli:

$\sigma_{\mathrm{t}}^{2}=\alpha_{0}+\alpha(\mathrm{L}) \varepsilon_{\mathrm{t}-1}^{2}+\beta(\mathrm{L}) \sigma_{\mathrm{t}-1}^{2}$

şeklinde genel olarak formüle edilmekte ve formülde yer alan $\alpha(\mathrm{L})$ ve $\beta$ (L), gecikme polinomlarını belirtmektedir. Genel formülü, $\mathrm{p}$ kadar koşullu varyans gecikmesi ve q kadar hata karelerinin gecikme sayısına göre tekrar GARCH $(\mathrm{p}, \mathrm{q})$ biçiminde ifade etmek gerekirse:

$\sigma_{\mathrm{t}}^{2}=\alpha_{0}+\alpha_{1} \varepsilon_{\mathrm{t}-1}^{2}+\alpha_{2} \varepsilon_{\mathrm{t}-2}^{2}+\ldots+\alpha_{\mathrm{q}} \varepsilon_{\mathrm{t}-\mathrm{q}}^{2}+\beta_{1} \sigma_{\mathrm{t}-1}^{2}+\beta_{2} \sigma_{\mathrm{t}-2}^{2}+\ldots+\beta_{\mathrm{p}} \sigma_{\mathrm{t}-\mathrm{p}}^{2}$

şeklinde de formül gösterilebilmektedir (Brooks, 2008, s. 394).

EGARCH modeli, GARCH modelinin bazı durumlarda yetersiz kalmas1 sonucunda Nelson (1991) tarafından önerilmiştir. EGARCH modeli:

$\ln \left(\sigma_{t}^{2}\right)=\omega+\beta \ln \left(\sigma_{t-1}^{2}\right)+\gamma \frac{u_{t-1}}{\sqrt{\sigma_{t-1}^{2}}}+\alpha\left[\frac{\left|u_{t-1}\right|}{\sqrt{\sigma_{t-1}^{2}}}-\sqrt{\frac{2}{\pi}}\right]$

biçiminde formüle edilmektedir. EGARCH modeli, $\log \left(\sigma_{t}^{2}\right)$ ile modellendiğinden dolayı, parametreleri negatif bile olsa aldığı değer pozitif olmaktadır. Bundan dolayı, model parametrelerine suni negatif olmayan kısıtlamalar ekleme gerekliliği ortaya çıkmamaktadır. Bunun yanı sıra, model formülünde asimetrilere izin verilmekte, çünkü volatilite ile getiri arasında var olan ilişki negatif ise $\gamma$ de negatif değer almaktadır (Brooks, 2008, s. 406).

\section{Araştırmanın Yöntem ve Bulguları}

Çalı̧̧mada, konvansiyonel hisse senedi piyasası olarak Borsa İstanbul 100 (BIST 100) ve İslami hisse senedi piyasası olarak da Katılım 30 (KAT 30) endekslerinde takvim anomalilerinin varlığı araştırılmak istenmektedir. Takvim anomalileri kapsamında, haftanın günü ve Ocak ayı etkileri araştırılmaktadır. Bu endeksler ile çalışmanın gerçekleştirilmek istenmesinin amacı, Türkiye özelinde asimetrik model kullanarak İslami ve konvansiyonel endeksler üzerinde karşılaştırmayı gerçekleştiren çalışmaya rastlanmadığından dolayı çalışmanın konu ile alakalı literatüre farklılık katarak derinlik kazandırabileceğinin düşünülmesidir. Çalışma, 7 Ocak 2011 ile 24 Temmuz 2020 tarihleri arasındaki günlük kapanış değerlerini kullanarak gerçekleştirilmiştir. Çalışmadaki tüm veriler, investing.com sitesinden elde edilmiştir. Günlük kapanış değerleri günlük nominal getiri serisine:

$$
r_{\mathrm{t}}=100 *\left[\ln \left(\mathrm{P}_{\mathrm{t}}\right)-\ln \left(\mathrm{P}_{\mathrm{t}-1}\right)\right]
$$

formülü yardımıyla dönüştürülmüştür. $r_{\mathrm{t}}$, zamanındaki hisse senedi piyasa endeksinin getirisi, $P_{t} t$ zamanındaki hisse senedi piyasa endeksinin kapanış değeri, $P_{t-1}$ ise $t-1$ zamanındaki hisse senedi piyasa endeksinin kapanış değerini göstermektedir. Takvim anomalilerinin belirlenebilmesi için hisse senedi piyasası endeks getirileri üzerinde, EGARCH modeli kullanılmıştır. Asimetrik model olan EGARCH sayesinde, endekslerde negatif veya pozitif yönde hangisinin volatiliteyi daha fazla artırdığı ortaya konulabilecektir. Çalışmadaki analiz ve model tahminleri, OxMetrics7 programı ile elde edilmiştir.

Çalışmanın bulguları, endeks getiri serilerine ait tanımlayıcı istatistiki bilgilerin verilmesi ile başlamakta, ardından EGARCH modeli sonuçları ve son olarak da kukla değişkenli EGARCH model sonuçları ile bulgular kısmı sonlandırılmaktadır. EGARCH (p, q) modeli için p,q=0,1,2 değerleri olmak üzere, tüm kombinasyonlar Akaike (AIC) ve Schwarz (SIC) Bilgi Kriterleri dikkate alınarak tespit edilmiş ve EGARCH $(1,1)$ model sonuçları tablolarda gösterilerek yorumlanmıştır. 
Tablo 1. KAT 30 endeks getiri serisinin tanımlayıcı istatistikleri

\begin{tabular}{llllllll}
\hline & KAT30 & Pazartesi & Salı & Çarşamba & Perşembe & Cuma & Ocak \\
\hline Veri & 2401 & 481 & 474 & 481 & 480 & 485 & 212 \\
\hline Ortalama & 0.000481 & 0.00087 & 0.00105 & -0.00065 & 0.000500 & 0.00110 & 0.00140 \\
\hline $\begin{array}{l}\text { Standart } \\
\text { Sapma }\end{array}$ & 0.012445 & 0.01470 & 0.01266 & 0.011172 & 0.01272 & 0.01048 & 0.01120 \\
\hline Çarpıklık & -0.92462 & -1.7614 & -0.15867 & -0.58520 & -1.0368 & -0.11148 & -0.27059 \\
\hline $\begin{array}{l}\text { Aşırı } \\
\text { Basıklık }\end{array}$ & 7.1975 & 12.021 & 3.9477 & 2.0511 & 4.9718 & 1.7603 & 0.58053 \\
\hline Minimum & -0.11049 & -0.11049 & -0.06270 & -0.04572 & -0.08150 & -0.03765 & -0.03470 \\
\hline Maksimum & 0.065996 & 0.05973 & 0.06600 & 0.041707 & 0.04174 & 0.04065 & 0.03952 \\
\hline
\end{tabular}

Tablo 1'de, Katılım 30 endeksine ait tüm veri seti, Pazartesi, Sal1, Çarşamba, Perşembe ve Cuma günleri ile Ocak ayına ait tanımlayıcı istatistik sonuçları gösterilmektedir. Çarpıklık değerine bakıldığında, seri sola çarpık asimetrik bir yapı göstermektedir. Aşırı basıklık değerleri ise, serinin leptokurtic yani normale göre daha sivri ve kalın kuyruklu dağılım sergilediğini ifade etmektedir. Ortalama değerleri sadece Çarşamba günü negatif değerde diğer günlerde ise pozitif değer almaktadır. Haftanın günleri içerisinde en yüksek pozitif ortalama getiri Cuma (0.00110), en düşük pozitif ortalama getiri ise Perşembe (0.000500) günü olarak tespit edilmiştir. Ocak ayında ise tüm veri seti için en yüksek ortalama getiri hesaplanmıştır.

Tablo 2. BIST100 endeks getiri serisinin tanımlayıcı istatistikleri

\begin{tabular}{llllllll}
\hline & BIST100 & Pazartesi & Salı & Çarşamba & Perşembe & Cuma & Ocak \\
\hline Veri & 2401 & 481 & 474 & 481 & 480 & 485 & 212 \\
\hline Ortalama & 0.0002291 & 0.0003307 & 0.0009141 & -0.00051 & 0.0003156 & 0.000392 & 0.001458 \\
\hline $\begin{array}{l}\text { Standart } \\
\text { Sapma }\end{array}$ & 0.014258 & 0.016381 & 0.014085 & 0.013044 & 0.015152 & 0.012221 & 0.013353 \\
\hline Çarpıklık & -0.64379 & -1.3335 & -0.11123 & -0.43063 & -0.50469 & -0.26112 & -0.12869 \\
\hline $\begin{array}{l}\text { Aşır1 } \\
\text { Basıklık }\end{array}$ & 4.1567 & 7.3188 & 1.6071 & 2.0729 & 2.8041 & 1.4737 & 0.83314 \\
\hline Minimum & -0.11063 & -0.11063 & -0.053474 & -0.05840 & -0.075337 & -0.05296 & -0.04327 \\
\hline Maksimum & 0.062371 & 0.062217 & 0.058104 & 0.045845 & 0.062371 & 0.045017 & 0.044310 \\
\hline
\end{tabular}

BIST100 endeksine ait tanımlayıcı istatistik değerleri, serinin sola çarpık asimetrik yapıda ve leptokurtic özellik sergilediğini göstermektedir. Katılım 30 endeksinde olduğu gibi Çarşamba günü, negatif ortalama getiriye sahip olan tek gün olarak belirlenmiştir. Salı (0.0009141) günü en yüksek pozitif ortalama getiriye sahipken, Perşembe (0.0003156) günü en düşük pozitif ortalama getiriye sahiptir. Ocak ayı Katılım 30 endeksinde olduğu gibi, tüm veri seti içinde en yüksek ortalama getiriye sahip olarak bulunmuştur.

Tablo 3. BIST 100 ve KAT 30 endeks getiri serilerine ait birim kök testi sonuçları

\begin{tabular}{lll}
\hline & BIST100 & KAT30 \\
\hline Augmented Dickey Fuller (ADF) & $-26.1725^{*}$ & $-24.9429^{*}$ \\
\hline Phillips-Perron (PP) & $-50.5588^{*}$ & $-46.3477^{*}$ \\
\hline KPSS & 0.0284375 & 0.054531 \\
\hline
\end{tabular}

BIST 100 ve KAT 30 endekslerinin getiri serilerine ait birim kök testi sonuçları Tablo 3'te verilmiştir. Birim kök testleri olan Augmented Dickey Fuller ve Phillips-Perron testlerinin "sıfır hipotezi" serinin durağan olmamasını, KPSS testinin "sıfır hipotezi" ise serinin durağan olmasını ifade etmektedir. Tabloda yer alan sonuçlara göre endeks getiri serilerinin durağan özellik sergiledikleri tespit edilmiştir. 
Tablo 4. Hisse senedi piyasası endeks getiri serilerinin EGARCH $(1,1)$ model sonuçları

\begin{tabular}{|c|c|c|}
\hline & BIST 100 & KAT 30 \\
\hline \multicolumn{3}{|c|}{ Ortalama Denklemi } \\
\hline$\alpha 0$ & $\begin{array}{l}0.000362377 \\
(0.0002583)\end{array}$ & $\begin{array}{c}0.000546282^{*} \\
(0.0002206)\end{array}$ \\
\hline \multicolumn{3}{|c|}{ Varyans Denklemi } \\
\hline$\omega$ & $\begin{array}{c}-0.735806 * \\
(0.04666) \\
\end{array}$ & $\begin{array}{c}-0.821852^{*} \\
(0.05441) \\
\end{array}$ \\
\hline$\alpha$ & $\begin{array}{c}0.270253 * \\
(0.04666)\end{array}$ & $\begin{array}{c}0.183026^{*} \\
(0.05441)\end{array}$ \\
\hline$\beta$ & $\begin{array}{c}0.945402 * \\
(0.01089) \\
\end{array}$ & $\begin{array}{c}0.927597 * \\
(0.01219)\end{array}$ \\
\hline$\gamma$ & $\begin{array}{c}-0.100615^{*} \\
(0.01268) \\
\end{array}$ & $\begin{array}{c}-0.113017^{*} \\
(0.01397) \\
\end{array}$ \\
\hline Q (50) & 58.702 & 69.308* \\
\hline Q2(50) & 48.934 & 45.543 \\
\hline ARCH (10) & 1.3846 & 1.3337 \\
\hline
\end{tabular}

* \%5 anlam düzeyinde istatistiksel anlamlılığı, ( ) p olasılık değerlerini, $\mathrm{Q}$ ve $\mathrm{Q}^{2}$ hata ve kareli getiri hata serilerinin bağımsızlık testi için Box Pierce, ARCH (10) ARCH-LM testini ifade etmektedir.

Tablo 4'te, BIST 100 ve KAT 30 endeks getiri serilerine ait EGARCH $(1,1)$ model sonuçları gösterilmektedir. Ortalama denkleminde, KAT 30 endeksi sabit değeri $\left(\alpha_{0}\right)$ anlamlı tespit edilmiştir. Varyans denkleminde ise her iki endeks için de sabit değerler istatistiki olarak anlamlı bulunmuştur. Volatilite kalıcılığını gösteren $\beta$ katsayısı değerine göre, her iki endeks için de volatilite kalıcılığının yüksek olduğunu, BIST 100 endeksinin (0.945402), KAT 30 endeksine (0.927597) göre daha yüksek volatilite kalıcıllğına sahip olduğu belirlenmiştir. Asimetri parametresi olan $\gamma$, her iki endeks getiri serisi için de negatif değerde ve $\% 1$ anlamlılık düzeyinde istatistiki olarak anlamlı tespit edilmiştir. Bu durum, endeksler için asimetri durumunun bulunduğunu ve negatif bilgi şoklarının volatilite üzerinde pozitif bilgi şoklarından daha baskın olduğunu ifade etmektedir. Getiri hata ve kareli getiri hata serilerinin bağımsızlık testi için yapılan Box Pierce sonuçları [KAT 30 için Q (50) değeri hariç], serilerin otokorelasyon sorunu olmadığını göstermektedir. ARCH-LM testi sonuçları da, artıklarda değişen varyans sorunu olmadığını belirtmektedir.

BIST 100 ve KAT 30 endekslerinde, haftanın günü ve Ocak ayının getiri ve volatilite üzerindeki etkilerini tespit edebilmek için kukla değişkenler olan Pazartesi, Salı, Çarşamba, Perşembe ve Cuma günleri ile Ocak ayı ortalama ve varyans denklemlerine eklenerek model tekrar kurulmuştur.

Tablo 5. Kukla değişkenli BIST 100 endeks getiri serisinin EGARCH $(1,1)$ model sonuçları

\begin{tabular}{|c|c|c|c|c|c|c|}
\hline & \multicolumn{6}{|c|}{ GBIST100 } \\
\hline & Pazartesi & Sal1 & Çarşamba & Perşembe & Cuma & Ocak \\
\hline & \multicolumn{6}{|c|}{ Ortalama Denklemi } \\
\hline \multirow[t]{2}{*}{$\alpha_{0}$} & 0.00163 & 0.00045 & 0.00130 & 0.00052 & 0.00064 & $0.00187 *$ \\
\hline & $(0.00212)$ & $(0.00081)$ & $(0.00086)$ & $(0.00095)$ & $(0.00055)$ & $(0.00084)$ \\
\hline \multirow[t]{3}{*}{$\alpha_{1}$} & -0.00071 & -0.00078 & -0.00078 & -0.00014 & -0.00034 & $-0.00165^{*}$ \\
\hline & $(0.00113)$ & $(0.00064)$ & $(0.00067)$ & $(0.00075)$ & $(0.00062)$ & $(0.00089)$ \\
\hline & \multicolumn{6}{|c|}{ Varyans Denklemi } \\
\hline \multirow[t]{2}{*}{$\omega$} & $-0.34550 *$ & $-0.64766^{*}$ & $-0.59246^{*}$ & $-0.71923 *$ & $-0.77767 *$ & $-0.71929 *$ \\
\hline & $(0.08370)$ & $(0.06988)$ & $(0.07059)$ & $(0.07074)$ & $(0.06375)$ & $(0.04483)$ \\
\hline \multirow[t]{2}{*}{$\alpha$} & $0.66055^{*}$ & $0.35838^{*}$ & $0.41351 *$ & $0.28684^{*}$ & $0.22840^{*}$ & $0.28678 *$ \\
\hline & $(0.08370)$ & $(0.06988)$ & $(0.07059)$ & $(0.07074)$ & $(0.06375)$ & $(0.04483)$ \\
\hline \multirow[t]{2}{*}{$\beta$} & $0.94849^{*}$ & $0.94688^{*}$ & $0.94731 *$ & $0.94553^{*}$ & $0.94379^{*}$ & $0.94834 *$ \\
\hline & $(0.01020)$ & $(0.01075)$ & $(0.01072)$ & $(0.01083)$ & $(0.01133)$ & $(0.01036)$ \\
\hline \multirow[t]{2}{*}{$\gamma$} & $-0.09972 *$ & $-0.10036^{*}$ & $-0.09914 *$ & $-0.10072 *$ & $-0.10123 *$ & $-0.10308 *$ \\
\hline & $(0.01224)$ & $(0.01261)$ & $(0.01263)$ & $(0.01266)$ & $(0.01288)$ & $(0.01247)$ \\
\hline
\end{tabular}




\begin{tabular}{lllllll}
\hline$\theta_{1}$ & $-0.42003^{*}$ & -0.13675 & $-0.22556^{*}$ & -0.026750 & 0.08751 & -0.00895 \\
& $(0.07963)$ & $(0.08273)$ & $(0.08630)$ & $(0.08443)$ & $(0.08719)$ & $(0.01443)$ \\
\hline $\mathrm{Q}(50)$ & 60.374 & 57.734 & 59.362 & 58.909 & 58.397 & 57.370 \\
\hline $\mathrm{Q}^{2}(50)$ & 55.894 & 48.985 & 51.686 & 49.504 & 47.649 & 48.908 \\
\hline $\begin{array}{l}\mathrm{ARCH} \\
(10)\end{array}$ & 1.7708 & 1.4833 & 1.5795 & 1.3992 & 1.2504 & 1.4014 \\
\hline
\end{tabular}

* \%5 anlam düzeyinde istatistiksel anlamlılı̆g , ( ) p olasılık değerlerini, $\mathrm{Q}$ ve $\mathrm{Q}^{2}$ hata ve kareli getiri hata serilerinin bağımsızlık testi için Box Pierce, ARCH (10) ARCH-LM testini ifade etmektedir.

Kukla değişkenler eklenerek gerçekleştirilen EGARCH $(1,1)$ model sonuçlarına göre, BIST 100 endeks getirisi üzerinde haftanın günü etkisinin olmadığı $\alpha_{1}$ katsayılarının istatistiki olarak anlamlı çıkmamasından anlaşılmaktadır. Ocak ayının ise, getiriler üzerinde negatif bir etkisinin olduğu kanıtlanmıştır. Volatilite üzerinde ise Pazartesi ve Çarşamba günlerinin negatif etkisinin olduğu, $\theta_{1}$ değerinin $\% 5$ anlamlılık düzeyinde anlamlı çıkması ile ortaya çıkarılmıştır. Ocak ayının ise volatilite üzerinde herhangi bir etkisinin olmadığ 1 belirlenmiştir. $\beta$ katsayısı en yüksek olan Pazartesi (0.94849) günü, volatilite kalıcılığı en yüksek olan gün olarak tespit edilmiştir. $\gamma$ parametresi, tüm günlerde ve Ocak ayında anlamlı olarak belirlenmiş ve BIST 100 endeks serisinin asimetrik özellik sergilediği ortaya çıkarılmıştır. Negatif değer alması ise, negatif bilgi şoklarının pozitif bilgi şoklarına göre daha fazla volatiliteyi artırdığını ifade etmektedir. Box Pierce ve ARCH-LM testi sonuçlarına bakıldığında ise, serinin otokorelasyon ve değişen varyans sorunu olmadığı belirlenmiştir.

Tablo 6. Kukla değişkenli KAT 30 endeks getiri serisinin EGARCH $(1,1)$ model sonuçları

\begin{tabular}{|c|c|c|c|c|c|c|}
\hline & \multicolumn{6}{|c|}{ GKAT30 } \\
\hline & Pazartesi & Sal1 & Çarşamba & Perşembe & Cuma & Ocak \\
\hline & \multicolumn{6}{|c|}{ Ortalama Denklemi } \\
\hline$\alpha_{0}$ & $\begin{array}{l}0.00202 * \\
(0.00093)\end{array}$ & $\begin{array}{l}0.00054 \\
(0.00065)\end{array}$ & $\begin{array}{l}0.00185^{*} \\
(0.00066)\end{array}$ & $\begin{array}{l}0.00096 \\
(0.00063)\end{array}$ & $\begin{array}{l}0.00107 * \\
(0.00047)\end{array}$ & $\begin{array}{l}0.00202 * \\
(0.00070)\end{array}$ \\
\hline$\alpha_{1}$ & $\begin{array}{l}-0.00080 * * \\
(0.00049)\end{array}$ & $\begin{array}{l}-0.00085 \\
(0.00052)\end{array}$ & $\begin{array}{l}-0.00109 * \\
(0.00050)\end{array}$ & $\begin{array}{l}-0.00034 \\
(0.00049)\end{array}$ & $\begin{array}{l}-0.00066 \\
(0.00052)\end{array}$ & $\begin{array}{l}-0.00160 * \\
(0.00074)\end{array}$ \\
\hline
\end{tabular}

\begin{tabular}{lllllll}
\hline \multicolumn{7}{c}{ Varyans Denklemi } \\
\hline$\omega$ & $-0.38953^{*}$ & $-0.72311^{*}$ & $-0.68863^{*}$ & $-0.74344^{*}$ & $-0.84353^{*}$ & -0.82194 \\
& $(0.08985)$ & $(0.07500)$ & $(0.07613)$ & $(0.07596)$ & $(0.06719)$ & $(0.05485)$ \\
\hline$\alpha$ & $0.61535^{*}$ & $0.28173^{*}$ & $0.31621^{*}$ & $0.26143^{*}$ & 0.16137 & $0.1830^{* *}$ \\
& $(0.08985)$ & $(0.07500)$ & $(0.07613)$ & $(0.07596)$ & $(0.06719)$ & $(0.05485)$ \\
\hline$\beta$ & $0.92888^{*}$ & $0.92865^{*}$ & $0.92946^{*}$ & $0.92768^{*}$ & $0.92685^{*}$ & $0.92775^{*}$ \\
& $(0.01172)$ & $(0.01218)$ & $(0.01217)$ & $(0.01200)$ & $(0.01235)$ & $(0.01205)$ \\
\hline$\gamma$ & $-0.11448^{*}$ & $-0.11296^{*}$ & $-0.11060^{*}$ & $-0.11402^{*}$ & $-0.11334^{*}$ & $-0.11586^{*}$ \\
& $(0.01379)$ & $(0.01392)$ & $(0.01383)$ & $(0.01398)$ & $(0.01405)$ & $(0.01406)$ \\
\hline$\theta_{1}$ & $-0.38953^{*}$ & -0.15726 & -0.20863 & -0.13026 & 0.04574 & 0.001288 \\
& $(0.08985)$ & $(0.08302)$ & $(0.08720)$ & $(0.08722)$ & $(0.08671)$ & $(0.01892)$ \\
\hline $\mathrm{Q}(50)$ & $68.923 *$ & 67.691 & $68.895^{*}$ & $70.536^{*}$ & $68.872^{*}$ & 67.839 \\
\hline $\mathrm{Q}(50)$ & 54.733 & 46.963 & 50.225 & 46.858 & 45.280 & 44.225 \\
\hline
\end{tabular}

*, ** \%5 ve \%10 anlam düzeyinde istatistiksel anlamlılı̆̆1, ( ) p olasılık değerlerini, Q ve $\mathrm{Q}^{2}$ hata ve kareli getiri hata serilerinin bağımsızlık testi için Box Pierce, ARCH (10) ARCH-LM testini ifade etmektedir.

KAT 30 endeksinin kukla değişkenli EGARCH $(1,1)$ model sonuçları Tablo 6'da gösterilmiştir. Getiride Pazartesi ve Çarşamba günlerinin anlamlı ve negatif değerde etkisinin olduğu, bunun yanı sıra Ocak ayının da negatif değerde etkisinin olduğu $\alpha_{1}$ değerinin istatistiki olarak anlamlı sonuç vermesinden tespit edilmiştir. Volatilite üzerinde ise sadece Pazartesi gününün, negatif değerde etkisinin olduğu belirlenmiştir. Ocak ayının volatilite üzerinde etkisinin olmadığ1 tespit edilmiştir. Volatilite kalıcılığının en yüksek olduğu gün, $0.92946 \beta$ katsayısı değeri ile Çarşamba günü olmuştur. Asimetri parametresi $\gamma$, bütün günler ve Ocak ayı için anlamlı 
ve negatif değerde bulunmuştur. Negatif bilgi şoklarının volatilite üzerinde pozitif bilgi şoklarına göre, volatiliteyi daha fazla artırdığını göstermektedir. $Q^{2}$ (50) değerlerine bakıldığında otokorelasyon sorunu olmadığ bulunmadığı belirlenmiştir.

\section{Sonuç ve Öneriler}

Takvim anomalisi, menkul kıymet fiyatlarındaki değişikliklerin belirli bir trend ya da tutarlı bir kalıp sonucunda meydana gelmesi olarak ifade edilmektedir. Takvim anomalisi sonucunda, yatırımcılar açısından hisse senedi piyasaları belirli aralıklarla öngörülebilir olabilmektedir. Fama Etkin Piyasa Hipotezi'nde yatırımcıların, çeşitli yatırım stratejileri kullanarak aşırı kazanç elde edemeyeceklerini ifade etmektedir. Ancak yatırımcılar, finansal piyasalardaki takvim etkilerini dikkate alarak ortalama piyasa getirisi üzerinde bir kazanç elde edebilmektedirler. Finans literatürü kapsamında yapılan takvim anomalisi çalışmaları, yatırımcılara belirli gün veya aylarda hisse senedi fiyat hareketlerini öngörebilmeleri için yol gösterici nitelikte olabilmektedirler.

Takvim anomalileri haftanın günü etkisi, Ocak ayı etkisi, yılın ayı etkisi, tatil etkisi, ay dönümü etkisi gibi anomalilerden oluşmaktadır. Ocak ayı etkisi, Ocak ayı boyunca hisse senedi fiyatlarında mevsimsel olarak bir artışın gerçekleştiğini ifade etmektedir. Haftanın günü etkisi ise, belirli bir hafta içi gün veya günlerde hisse senetleri getirilerinin, mevsimsel olarak uzun bir süre boyunca haftanın diğer günlerine kıyasla sürekli olarak daha yüksek veya daha düşük getiri sağladığı gün veya günlerin varlığını belirtmektedir.

Çalışma, Türkiye hisse senedi piyasasının İslami ve konvansiyonel endekslerinde haftanın günü ve Ocak ayı etkilerinin varlığını belirlemek için yapılmaktadır. İslami endeks olarak Kat1lım 30, konvansiyonel endeks olarak da Borsa İstanbul 100 endekslerinin, 7 Ocak 2011 ile 24 Temmuz 2020 tarihleri arasındaki günlük kapanış fiyatları üzerinde analiz gerçekleştirilmiştir. $\mathrm{Bu}$ tarih aralığının seçilmesinin sebebi ise, Katılım 30 endeksinin o tarihten itibaren başlaması ve borsa endekslerinden iki sıfır atılmadan önceki son iş günü olmasıdır. Endeks getiri serileri üzerinde, EGARCH modeli kullanılarak analizler gerçekleştirilmiştir.

Endekslerin getiri serileri üzerinde gerçekleştirilen EGARCH $(1,1)$ model sonuçlarına göre, KAT 30 endeksinin pozitif getiri sağladığı $\alpha_{0}$ değerinin istatistiki olarak anlamlı çıkmasından tespit edilmiştir. Volatilite kalıcılığını gösteren $\beta$ katsayısı, her iki endeks için de volatilite kalıcılığının yüksek olduğunu, BIST 100 endeksinin (0.945402) KAT 30 endeksine (0.927597) göre daha yüksek volatilite kalıcıllğına sahip olduğunu göstermektedir. Asimetri parametresi olan $\gamma$, her iki endeks getiri serisi içinde negatif ve istatistiki olarak anlamlı tespit edilmiştir. Bu durum, endeksler için asimetri durumunun olduğunu ve negatif bilgi şoklarının volatilite üzerinde pozitif bilgi şoklarından daha baskın olduğunu ifade etmektedir.

Haftanın tüm günleri ve Ocak ayı kukla değişken olarak eklenerek yapılan EGARCH (1, 1) model sonuçları, BIST 100 endeks getirisi üzerinde haftanın günü etkisinin olmadığını, KAT 30 endeks getirisinde ise Pazartesi ve Çarşamba günlerinin anlamlı ve negatif değerde etkisinin olduğu, $\alpha_{1}$ değerinin istatistiki olarak anlamlı sonuç vermesinden ortaya konulmuştur. Yatırımcılar KAT 30 endeksinde, Pazartesi günü Çarşamba gününe kıyasla daha fazla getiri elde etmektedirler. Ocak ayının ise, her iki endeks getirisi üzerinde negatif değerde etkisinin olduğu kanıtlanmıştır. BIST 100 endeksi değeri (-0.00165), KAT 30 endeksi değerine (-0.00160) göre daha yüksek tespit edildiği için, Ocak ayında BIST 100 endeksi yatırımcılarına daha az getiri kazandırmaktadır. Volatilite üzerinde ise, BIST 100 endeksi için Pazartesi ve Çarşamba günlerinin, KAT 30 endeksi için de Pazartesi gününün negatif değerde etkisinin olduğu $\theta_{1}$ değerinin istatistiksel olarak anlamlı olmasından anlaşılmaktadır. BIST 100 endeksi volatilitesinde, Pazartesi günü -0.42003 değeri ile Çarşamba gününe göre daha yüksek negatif değer almakta dolayısıyla volatilite o gün daha yüksek olmaktadır. Ocak ayının ise, her iki endeks volatilitesi üzerinde herhangi bir etkisinin olmadığ 1 tespit edilmiştir. Asimetri parametresi olan $\gamma$ hem BIST 100 hem de KAT 30 endeksi için Pazartesi, Salı, Çarşamba, Perşembe ve Cuma günleri 
ile Ocak ayı için anlamlı ve negatif değerde bulunmuştur. Bu sonuç, negatif bilgi şoklarının volatilite üzerinde pozitif bilgi şoklarına göre daha baskın olduğunu yani volatiliteyi daha fazla artırdığını ifade etmektedir.

Çalışma sonuçları Berument \& Kıymaz (2001), Atakan (2008), Korkmaz vd. (2010), Konak ve Kendirli (2014) ve Anjum (2020) ile benzer sonuçlar göstermektedir. Yapılan çalışmanın, Türkiye özelinde asimetrik model kullanarak bu tür karşılaştırmayı gerçekleştiren çalışmaya rastlanmadığından dolayı konu ile alakalı literatüre derinlik kazandıracağı düşünülmektedir.

Ayrıca yatırımcılar açısından ortaya çıkan sonuçlar, analize tabi tutulan endeksler üzerinde işlem yapmak isteyen yatırımcılara almayı düşündükleri yatırım pozisyonları hakkında bilgiler vermekte ve işlemlerini almak istedikleri risk ve getiri seviyesine göre analiz sonucunda belirlenen gün ve ay için değişik stratejiler oluşturabilmelerine yol gösterici niteliğinde olabileceği düşünülmektedir.

\section{Kaynakça}

Anjum, S. (2020). Impact of market anomalies on stock exchange: a comparative study of KSE and PSX. Future Business Journal, 6 (1), 1-11. DOI: 10.1186/s43093-019-0006-4

Arı, A. ve Yüksel, Ö. (2017). BİST 100'de haftanın günü anomalisi: ekonometrik bir analiz. Finans \& Politik ve Ekonomik Yorumlar, 54 (632), 77-89.

Atakan, T. (2008). İstanbul Menkul Kıymetler Borsası'nda haftanın günü etkisi ve Ocak ayı anomalilerinin ARCH-GARCH modelleri ile test edilmesi. İstanbul Üniversitesi İsletme Fakültesi Dergisi, 37 (2), 98-110.

Berument, H. ve Kiymaz, H. (2001). The day of the week effect on stock market volatility. Journal Of Economics And Finance, 25 (2), 181-193. DOI: 10.1007/BF02744521

Bollerslev, T. (1986). Generalized autoregressive conditional heteroskedasticity. Journal of Econometrics, 31 (3), 307-327. https://doi.org/10.1016/0304-4076(86)90063-1

Brooks, C. (2008). Introductory Econometrics for Finance, Second Edition, New York: Cambridge University Press.

Caporale, G. M. ve Zakirova, V. (2017). Calendar anomalies in the Russian stock market. Russian Journal of Economics, 3, 101-108. https://doi.org/10.1016/j.ruje.2017.02.007

Choudhry, T. (2000). Day of the week effect in emerging Asian stock markets: Evidence from The GARCH Model. Applied Financial Economics, 10 (3), 235-242. https://doi.org/10.1080/096031000331653

Engle, R. F. (1982). Autoregressive conditional heteroskedasticity with estimates of the variance of U.K. inflation. Econometrica, 50 (4), 987-1007. DOI: 10.2307/1912773

Engle, R. F. (2001). GARCH 101: the use of ARCH/GARCH models in applied econometrics. Journal of Economic Perspectives, 15 (4), 157-168. DOI: 10.1257/jep.15.4.157

Giovanis, E. (2016). The Month-of-the-year effect: evidence from GARCH models in fifty five stock markets. Aydın Iktisat Fakültesi Dergisi, $1 \quad$ (1), 20-49. http://dx.doi.org/10.2139/ssrn.1595706

Güç, E., Saçan, E, ve Kaplan Yıldırım, R. (2016). Borsa İstanbul'da haftanın günü anomalisinin ARCH, GARCH ve OLS modelleri ile test edilmesi. Uluslararası Sosyal Araştırmalar Dergisi, 9 (44), 1084-1094. DOI: 10.17719/jisr.20164420178 
Jebran, K. ve Chen, S. (2017). Examining anomalies in Islamic equity market of Pakistan. Journal of Sustainable Finance \& Investment, $7 \quad$ (3), $\quad$ s. $\quad 275-289$. https://doi.org/10.1080/20430795.2017.1289455

Jindal, N. (2019), Calendar anomalies in Indian stock market: an empirical analysis. IUP Journal of Financial Risk Management; Hyderabad, 16 (4), 23-29.

Karcıoğlu, R. ve Özer, N. (2017). BIST’ de haftanın günü ve tatil etkisi anomalilerinin getiri ve oynaklık üzerindeki etkisinin incelenmesi. Karadeniz Teknik Üniversitesi Sosyal Bilimler Enstitüsü Sosyal Bilimler Dergisi, 7 (14), 457-483.

Khan, M. S. R. ve Rabbani, N. (2019). Market conditions and calendar anomalies in Japanese stock returns. Asia-Pacific Financial Markets, 26 (2), 187-209.

Khanh, P. D. ve Dat, P. T. (2020). Efficient market hypothesis and calendar effects: empirical evidences from the Vietnam stock markets. Accounting, 6 (5), 893-898. DOI: 10.5267/j.ac.2020.5.005

Kinateder, H., Weber, K. ve Wagner, N. F. (2019). Revisiting calendar anomalies in BRICS countries. Bulletin of Monetary Economics and Banking, 22 (2), 213-236. https://doi.org/10.21098/bemp.v22i2.1092

Konak, F. ve Kendirli, S. (2014). Küresel finansal kriz sürecinde BİST 100 endeksi'nde haftanın günleri etkisinin analizi. Süleyman Demirel Üniversitesi İktisadi ve İdari Bilimler Fakültesi Dergisi, 19 (2), 275-286.

Korkmaz, T., Başaran, Ü. ve Çevik, E. İ. (2010). Yaz saati uygulaması anomalisinin İMKB 100 endeks getirisine etkisinin test edilmesi. Ege Akademik Bakış. 10 (4), 1139-1153.

Latif, M., Arshad S., Fatima M. ve Farooq S. (2011). Market efficiency, market anomalies, causes, evidences, and some behavioral aspects of market anomalies. Research Journal of Finance and Accounting, 2 (9/10), 1-13.

Nelson, D. B. (1991). Conditional heteroskedasticity in asset returns: a new approach. Econometrica, 59 (2), 347-370. DOI: 10.2307/2938260

Öncü, M. A., Ünal, A. ve Demirel, O. (2017). The day of the week effect in Borsa Istanbul; a GARCH model analysis. Uluslararası Yönetim İktisat ve İşletme Dergisi, 13 (3), 521-534. DOI: 10.17130/ijmeb.2017331332

Öztürk, M. B., Uysal, M., Arslan, H. ve Kayhan, T. (2018). The impact of calendar anomalies on stock return and volatility: evidence from Turkish stock market. Ömer Halisdemir Üniversitesi Iktisadi ve İdari Bilimler Fakültesi Dergisi, $11 \quad$ (1), 221-238. https://doi.org/10.25287/ohuiibf.381031

Rozeff, M. S. ve Kinney W. R. (1976). Capital market seasonality: the case of stock returns. Journal of Financial Economics, 3 (4), 379-402. https://doi.org/10.1016/0304405X(76)90028-3

Singh, S. ve Das, C. (2020). Calendar anomalies in the banking and it index: the Indian experience. Asian Economic and Financial Review, 10 (4), 439-448. DOI: 10.18488/journal.aefr.2020.104.439.448

Tajinder (2019). Analysis of stock market calendar anomalies and stakeholders behavior (Yayımlanmamış doktora tezi). Lovely Professional University.

Thaler, R. H. (1987). Anomalies the January effect. Economic Perspectives, 1 (1), 197-201. DOI: 10.1257/jep.1.1.197 
Yardımc1, B. ve Erdem, S. (2020). The day of the week effects in stockmarkets of countries with predominantly Muslim populations. International Journal of Islamic and Middle Eastern Finance and Management, 13 (2), 195-218. https://doi.org/10.1108/IMEFM-06-2018-0199

\section{ETİK ve BİLIMSEL İLKELER SORUMLULUK BEYANI}

$\mathrm{Bu}$ çalışmanın tüm hazırlanma süreçlerinde etik kurallara ve bilimsel atıf gösterme ilkelerine riayet edildiğini yazar(lar) beyan eder. Aksi bir durumun tespiti halinde Afyon Kocatepe Üniversitesi Sosyal Bilimler Dergisi'nin hiçbir sorumluluğu olmayıp, tüm sorumluluk makale yazarlarına aittir.

\section{ARAŞTIRMACILARIN MAKALEYE KATKI ORANI BEYANI}

1. yazar katk1 oranı : \%100 